\title{
Analysis of the Interaction between Polymer and Surfactant in Aqueous Solutions for Chemical Enhanced Oil Recovery
}

\section{Réka Kothencz, Roland Nagy, László Bartha, Judit Tóth \& Árpád Vágó}

To cite this article: Réka Kothencz, Roland Nagy, László Bartha, Judit Tóth \& Árpád Vágó (2017): Analysis of the Interaction between Polymer and Surfactant in Aqueous Solutions for Chemical Enhanced Oil Recovery, Particulate Science and Technology, DOI: 10.1080/02726351.2017.1321073

To link to this article: $\mathrm{http}: / / d x . d o i . o r g / 10.1080 / 02726351.2017 .1321073$

Accepted author version posted online: 27

Apr 2017

Submit your article to this journal $\pi$

Џ Article views: 2

Q View related articles $๘$

View Crossmark data $₫$ 


\title{
Analysis of the Interaction between Polymer and Surfactant in Aqueous Solutions for Chemical Enhanced Oil Recovery
}

\author{
Réka Kothencz*
}

Department of MOL-Hydrocarbon and Coal Processing, University of Pannonia, Veszprém, Hungary

Roland Nagy

Department of MOL-Hydrocarbon and Coal Processing, University of Pannonia, Veszprém, Hungary

\section{László Bartha}

Department of Chemical Engineering Science, University of Pannonia, Veszprém, Hungary

Judit Tóth

Research Institute of Chemical and Process Engineering, University of Pannonia, Veszprém, Hungary

Institute of Materials and Environmental Chemistry, Research Centre for Natural Sciences, Hungarian Academy of Sciences, Budapest, Hungary

Árpád Vágó

MOL plc, Research and Business Development, Budapest, Hungary 
Address correspondence to Réka Kothencz, Department of MOL-Hydrocarbon and Coal

Processing, University of Pannonia, 8200 Veszprém, Hungary. +3688624000/6168. E-mail:

kothenczr@almos.uni-pannon.hu, nroland@ almos.uni-pannon.hu

\begin{abstract}
Most petroleum reservoirs are subjected to Improved and Enhanced Oil Recovery (IOR and EOR) processes following secondary recovery. EOR involves the application of external forces and substances to improve the chemical and physical interactions in hydrocarbon reservoirs in order to improve preferable recovery conditions. The process of chemical flooding with solutions of polymers and surfactants can be used for developing oil exploitation. Studying the interaction between surfactants and polymers is indispensable for successful oil recovery. The interaction between non-ionic \& anionic surfactants and polymers in ternary mixtures was examined at different concentrations and temperatures by dynamic light scattering and gel permeation chromatography. The hydrodynamic size of surfactant-polymer composites was higher than the particle size of individual components indicating a formation of associates. The size of associates increased by increasing the concentration of the surfactants and the temperature. It could be supposed that the polymer formed a mixed micelle with the surfactants. Gel permeation chromatography has confirmed the increase in molecular weight of the associate formed by surfactants and polymers.
\end{abstract}

Keywords: enhanced oil recovery, gel permeation chromatography, hydrodynamic size, polymer-surfactant interaction

\title{
INTRODUCTION
}


Energy demand worldwide has necessitated the need for EOR (Enhanced Oil Recovery) processes. Approximately two-thirds of the oil remains in an average oil reservoir after primary and secondary waterflooding production. The residual oil is trapped in the pore structure of the reservoir. The oil displacement efficiency can be increased by decreasing the oil viscosity or by reducing the capillary forces or the interfacial tension between the water and oil phases. Flooding by the aqueous solution of surfactants and polymer mixtures is an improved technique for enhancing the oil displacement efficiency. The role of the surfactant is to reduce the interfacial tension between the crude oil and water and the polymer can modify the flow properties (Wang et al. 2009; Li and Yin 2013; Suman et al. 2014; Li et al. 2016). Interfacial tension reduction and wettability alteration of the reservoir rocks are the two main mechanisms of the oil recovery process involving the employment of surfactant flooding (Ahmadi, Galedarzadeh, and Shadizadeh 2015).

Environmental impacts, surfactant expenditure, and oil price are the three main parameters that have an effect on the robustness of surfactant flooding in oil reservoirs (Ahmadi, Galedarzadeh, and Shadizadeh 2015). Plant-derived surfactants have proven remarkable considering their ease of generation, environmentally friendliness and low cost (Ahmadi and Shadizadeh 2013; Ahmadi et al. 2014; Ahmadi and Shadizadeh 2015).

Surfactant and polymer flooding face some problems like adsorption onto rock. The adsorption behaviour of implemented chemicals has a vital role in terms of the robustness and effectiveness of chemical flooding. As the surfactant concentration increases, the magnitude of adsorption density on the surface of carbonate rocks increases until it reaches the saturation point (Ahmadi and Shadizadeh 2013; Zendehboudi et al. 2013). 
The interaction between oppositely charged polymer-surfactant mixtures in the solutions was studied using surface tension measurements (Ansari, Kamil, and Kabir-ud-Din 2013). It was observed that the cationic surfactants interact strongly with the oppositely charged anionic polymer. The analysis of the critical aggregation concentration and the critical micelle concentration of cationic surfactants indicates the existence of strong electrostatic interactions.

Light scattering and viscometric measurements of high molecular weight polyacrylamide and a non-ionic surfactant in an aqueous solution were carried out (Mya, Jamieson, and Sirivat 1999). It was determined that the surfactant molecules induced a significant increase in the size of the polymer chains at higher surfactant concentrations. Polyacrylamides with different molecular weights interacted with the surfactant quite similarly.

The objective of this paper was to investigate the interaction between non-ionic $\&$ anionic surfactants and polymers in ternary mixtures used for EOR at different temperatures. In a previous paper the interaction between the components investigated by dynamic light scattering has already been reported (Nagy et al. 2014). The interaction between the surfactants and the polymers could be proven by measuring the particle size of the composites: the composites of the polymers and surfactants exhibited higher particle sizes than the polymers and surfactants separately. The presence of polymeric chains induced the formation of micelles. Hydrophobic interactions were the main attractive forces and the presence of oppositely charged species could result in any other enhanced interactions (Hansson and Lindman 1996; Kwak 1998; Holmberg et al. 2002). Gel permeation chromatography (GPC) is an uncommon method of investigating the polymersurfactant systems prepared for EOR (Veggeland and Austad 1993).

Our objective was also to determine if gel permeation chromatography is suitable for detecting interactions. 


\section{MATERIALS AND METHODS}

The non-ionic and anionic surfactants were developed and produced by the University of Pannonia. A fatty acid-alkanol-amine-ester derivative was used as a non-ionic surfactant which is the reaction product of a fatty acid derivative and diethanolamine. The anionic surfactant was the alkyl-( $\left.\mathrm{C}_{12}\right)$-aryl-sulfonic acid derivative. The flow-modifier polymer was a partially hydrolysed synthetic polyacrylamide produced by the SNF Group. The surfactants and the polymer were dissolved in brine (obtained from Algyö, Hungary). In Tables 1 and $\mathbf{2}$ the properties of brine and the flow-modifier polymer are shown, respectively.

A surfactant package consisting of a constant ratio of non-ionic to anionic surfactants (40:60) at different overall concentrations $\left(5,10,15,20\right.$ and $\left.25 \mathrm{~g} / \mathrm{dm}^{3}\right)$ was used during measurements. The surfactant solutions were prepared in brine then mixed with the flow-modifier polymer at a final concentration of $1 \mathrm{w} / \mathrm{w} \%$ and the solutions were measured at 50, 60, 70 and $80^{\circ} \mathrm{C}$.

\section{Dynamic Light Scattering Measurements}

The particle size and distribution of the samples were measured by dynamic light scattering using a Malvern Zetasizer Nano ZS instrument. The hydrodynamic radius was determined by Photon Correlation Spectroscopy (also known as dynamic light scattering) and estimated from the particles' diffusivity using the Stokes-Einstein equation. The apparatus uses a $5 \mathrm{~mW}$ HeNe laser at a wavelength of $633 \mathrm{~nm}$. The measurement range of the instrument is $0.3-100,000 \mathrm{~nm} .5 \mathrm{ml}$ of the samples were treated for 2 minutes using an ultrasound disintegrator (Type: UD-11) at a frequency of $22 \mathrm{kHz}$ and a power of $100 \mathrm{~W}$ to achieve a transparent appearance before the particle size was measured. Independent triplicates of each sample over 5 runs were measured in a 
PCS8501 square glass cuvette. The average peak values of particle diameter (nm) for the different samples were calculated.

\section{Gel Permeation Chromatography}

The molecular weight and the distribution of the samples were determined by gel permeation chromatography in Millipore water. The measurements were carried out by a LaChrom Merck chromatograph equipped with a refractive index (RI) detector. Two serially connected PL aquagel-OH MIXED-M $8 \mu \mathrm{m}$ columns were applied to determine measurements. The concentration of samples was $0.025 \mathrm{~g} / 5 \mathrm{ml}$ of water and the flow rate was $1 \mathrm{ml} / \mathrm{min}$ at $2.5 \mathrm{MPa}$. The device consisted of the following components: L-7100 pump; L-7200 autosampler; L-7490 refractive index detector; L-7614 gas discharge lamp; D-7000 interface module; and D-7000 HPLC System Manager (HSM) software. The molecular weight of each component was estimated based on Pullulan standards (polysaccharides). The molecular weights were estimated and it may be supposed that these procedures can be applied for the characterization of size analysis. In the case of the mentioned GPC set-up the RSD of the measurements was $<5 \%$.

\section{RESULTS AND DISCUSSION}

\section{Particle Size Analysis}

The dependence of particle size on temperature using different concentrations of the surfactants and a flow-modifier polymer in $1 \mathrm{~g} / \mathrm{cm}^{3}$ can be seen in Figure 1.

The curves of Figure 1 show a significantly higher particle size of the combinations of surfactants and polymer in aqueous solutions formed at higher temperatures. Both the increased temperature and increased concentration of surfactants caused the additional growth of the 
hydrodynamic diameter of the dissolved colloidal particles. The increase in the hydrodynamic diameter can be explained by the interaction between the polymer and surfactants which resulted in the formation of mixed micelle associates. The temperature dependence can be interpreted in terms of the swell of the polymer. The concentration dependence can be illustrated by the number of linkages between surfactants and the polymer.

The surfactant concentration range in industrial applications is broad. Therefore, it is important to examine the effect of concentration on the particle size of the associates. According

to Figure 1 when the overall concentration of the surfactants exceeded $15 \mathrm{~g} / \mathrm{l}$, the particle size increased significantly as the temperature increased. This effect can be explained by the formation of different associates composed of several molecules. As a result of even a small increase in concentration, the spherical micelle could be transformed into a cylinder or other forms (Holmberg et al. 2002; Yang et al. 2013). The possible effect of this transformation was that the width of the gel permeation chromatograms increased significantly (Figure 2).

\section{Gel Permeation Chromatography}

In order to verify the particle size, gel permeation chromatography measurements were performed to obtain information about the average molecular weight of associates. Both the surfactants and the polymer can be investigated by gel permeation chromatography. Therefore, it was supposed that a polymer-surfactant associate can also be formed.

In Figure 2 the gel permeation chromatogram of surfactants, polymer and polymersurfactant associates can be observed. The applied concentrations of surfactants and the polymer were 15 and $1 \mathrm{~g} / \mathrm{l}$, respectively. 
The estimation was based on a polymer-surfactant standard so it is only suitable for relative comparisons because of the different refractive index conditions of various components.

It was determined that the micelles composed of a polymer-surfactant mixture were not degraded during GPC measurements because of the strong interactions they exhibit, so the measured data did not yield the real molecular weight of the compounds. However, the size of the mixed micelles can be characterized by the change in these molecular weights (Da). It was found that the molecular weights of the polymer-surfactant solutions were higher than the molecular weights of the polymer or surfactants.

The average molecular weights are represented in Table 3, $7.98 \cdot 10^{5} \mathrm{Da}$ for surfactants and $7.33 \cdot 10^{6} \mathrm{Da}$ for polymer-surfactant associates based on Pullulan (polysaccharide) standards.

By comparing the molecular weight data with the size distribution of the components and composites, it would seem that the growth in the particle size of the polymer-surfactant mixtures is a result of the formed polymer-surfactant associates. The broader distribution curve of the polymer-surfactant solutions also supports this assumption (compared with the polymer and surfactant solutions individually). Thus the previously discussed interaction was supported by these GPC results.

The temperature dependence was also studied using water-based gel permeation chromatography (Figrue 3). The rise in the molecular weight by increasing the temperature is only slightly comparable with particle size growth. This indicated that the growth in the size of the associates was caused more by the swelling of the composites than the increased number of the components in the associates. By increasing the temperature the size and the molecular weight of associates has also increased because of the swollen polymer and the interaction. 


\section{CONCLUSION}

The interaction between the polymer and the surfactants is of great importance in EOR for screening polymer-surfactant associates. The particle size of the flow-modifier polymer, surfactants and polymer-surfactant mixtures dissolved in brine were investigated and applied to chemical enhanced oil recovery. The interactions between the polymer and surfactants were proved by dynamic light scattering and gel permeation chromatography methods. The measurements were carried out in different concentrations of surfactants and the temperature dependence of the components was also examined. It can be assumed that the hydrodynamic size of the associates depends both on the concentration of the surfactants and on the temperature. The growth in particle size indicated an interaction between the polymer and the surfactants. The GPC measurements showed an increase in the average molecular weight of the composites when compared with the individual components of the polymer and surfactants. Later the formation of larger associates was also indicated between the polymer and surfactants. It can be supposed that the polymer formed a mixed micelle with the surfactants. The increase in particle size as a result of increasing the temperature was caused by the swelling of the polymer.

If an interaction is realized between the surfactants and the polymer, surfactant-polymer flooding is more likely to occur. Dynamic light scattering and gel permeation chromatography are suitable methods to prove this interaction. Therefore, they can form part of an efficient selection method for CEOR.

\section{References}

Ahmadi, M. A., Y. Arabsahebi, S. R. Shadizadeh, and S. S. Behbahani. 2014. Preliminary evaluation of mulberry leaf-derived surfactant on interfacial tension in an oil-aqueous system: EOR application. Fuel 117:749-55. doi:10.1016/j.fuel.2013.08.081 
Ahmadi, M. A., M. Galedarzadeh, and S. R. Shadizadeh. 2015. Wettability alteration in carbonate rocks by implementing new derived natural surfactant: Enhanced oil recovery applications. Transport in Porous Media 106:645-67.

Ahmadi, M. A., and S. R. Shadizadeh. 2013a. Implementation of a high-performance surfactant for enhanced oil recovery from carbonate reservoirs. Journal of Petroleum Science and Engineering 110:66-73. doi:10.1016/j.petrol.2013.07.007

Ahmadi, M. A., and S. R. Shadizadeh. 2013b. Experimental investigation of adsorption of a new nonionic surfactant on carbonate minerals. Fuel 104:462-67. doi:10.1016/j.fuel.2012.07.039

Ahmadi, M. A., and S. R. Shadizadeh. 2013c. Induced effect of adding nano silica on adsorption of a natural surfactant onto sandstone rock: Experimental and theoretical study. Journal of Petroleum Science and Engineering 112:239-47. doi:10.1016/j.petrol.2013.11.010

Ahmadi, M. A., and S. R. Shadizadeh. 2015. Experimental and theoretical study of a new plant derived surfactant adsorption on quartz surface: Kinetic and isotherm methods. Journal of Dispersion Science and Technology 36:441-52. doi:10.1080/01932691.2013.860035

Ansari, A. A., M. Kamil, and K. Kabir-ud-Din. 2013. Interaction of oppositely charged polymersurfactant system based on surface tension measurements. Journal of Petroleum Science Research 2:35-40.

Hansson, P., and B. Lindman. 1996. Surfactant-polymer interactions. Current Opinion in Colloid Interface Science 1:604-13.

Holmberg, K., B. Jönsson, B. Kronberg, and B. Lindman. 2002. Surfactants and polymers in aqueous solution. John Wiley \& Sons.

Kwak, J. C. T. 1998. Polymer-surfactant systems. New York: Marcel Dekker.

Li, J. J., H. Q. Jiang, K. Xiao, Z. T. Zhang, and Y. T. Wang. 2016. The relationship between the sweep efficiency and displacement efficiency of function polymer in heterogeneous reservoir after polymer flood. Particulate Science and Technology 1:1-6. doi:10.1080/02726351.2016.1160461

Li, Y., and L. Yin. 2013. A new surfactant flooding model for low permeability reservoirs. Open Journal of Fluid Dynamics 3:1-8. doi:10.4236/ojfd.2013.31001

Mya, K. Y., A. M. Jamieson, and A. Sirivat. 1999. Interactions between the nonionic surfactant and polyacrylamide studied by light scattering and viscometry. Polymer 40:5741-49. doi:10.1016/s0032-3861(98)00811-8

Nagy, R., L. Bartha, J. Tóth, and Á. Vágó. 2014. Study on characteristics of Micelles formed by surfactants and polymer mixtures for enhanced oil recovery. Chemical Engineering Transactions 36.

Suman, Y. K., E. Shirif, H. Ibrahim, and A. Ala-Ktiwi. 2014. Investigating improved oil recovery in heavy oil reservoirs. World Journal of Engineering and Technology 2:23-31. doi: $10.4236 /$ wjet.2014.21003

Veggeland, K., and T. Austad. 1993. An evaluation of gel permeation chromatography in screening surfactant/polymer interaction of commercial products in saline aqueous solutions. Colloids and Surfaces A: Physicochemical and Engineering Aspects 76:73-80. doi:10.1016/0927-7757(93)80063-k

Wang, H., X. Cao, J. Zhang, and A. Zhang. 2009. Development and application of dilute surfactant-polymer flooding system for Shengli oilfield. Journal of Petroleum Science and Engineering 65 (1-2):45-50. doi:10.1016/j.petrol.2008.12.021 
Yang, H., D. Yu, H. Wang, Q. Xie, J. Wu, and J. Wang. 2013. Aggregation behaviour of amphiphilic PAMAM-based hyperbranched polymer in the presence of conventional small molecular surfactants. Advances in Chemical Engineering 3:11-18. doi:10.4236/aces.2013.33a1002

Zendehboudi, S., M. A. Ahmadi, A. R. Rajabzadeh, N. Mahinpey, and I. Chatzis. 2013. Experimental study on adsorption of a new surfactant onto carbonate reservoir samples Application to EOR. The Canadian Journal of Chemical Engineering 91:1439-49. doi:10.1002/cjce.21806 
Table 1. The properties of brine

\begin{tabular}{|l|l|}
\hline Property & Unit \\
\hline Conductivity $\left(20^{\circ} \mathrm{C}\right)$ & $3.22 \mathrm{mS} / \mathrm{cm}$ \\
\hline $\mathrm{pH}$ & 8.5 \\
\hline Potassium & $14.8 \mathrm{mg} / \mathrm{l}$ \\
\hline Sodium & $1086 \mathrm{mg} / 1$ \\
\hline Magnesium & $2.32 \mathrm{mg} / 1$ \\
\hline Calcium & $15.1 \mathrm{mg} / 1$ \\
\hline Carbonate & $396 \mathrm{mg} / \mathrm{l}$ \\
\hline Hydrocarbonate & $1672 \mathrm{mg} / \mathrm{l}$ \\
\hline
\end{tabular}


Table 2. The properties of the flow-modifier polymer

\begin{tabular}{|l|l|}
\hline Property & Unit \\
\hline Sulfonated ratio & $25 \%$ \\
\hline Applied concentration & $1 \mathrm{~g} / \mathrm{dm}^{3}$ \\
\hline
\end{tabular}


Table 3. The molecular weight of the surfactants, the polymer and the polymer-surfactant associates at $25^{\circ} \mathrm{C}$

\begin{tabular}{|l|l|l|l|}
\hline & $\mathrm{M}_{\mathrm{n}}[\mathrm{Da}]$ & $\mathrm{M}_{\mathrm{w}}[\mathrm{Da}]$ & $\mathrm{M}_{\mathrm{P}}[\mathrm{Da}]$ \\
\hline Surfactants & $2.54 \cdot 10^{5}$ & $7.98 \cdot 10^{5}$ & $7.44 \cdot 10^{5}$ \\
\hline Polymer & $5.52 \cdot 10^{6}$ & $1.44 \cdot 10^{6}$ & $4.12 \cdot 10^{5}$ \\
\hline Polymer-surfactant associates & $7.05 \cdot 10^{5}$ & $7.33 \cdot 10^{6}$ & $2.88 \cdot 10^{6}$ \\
\hline
\end{tabular}


Figure 1. The particle size dependence on temperature and the different concentrations of the surfactants dissolved in brine containing flow-modifier polymer at a concentration of $1 \mathrm{~g} / \mathrm{cm}^{3}$.

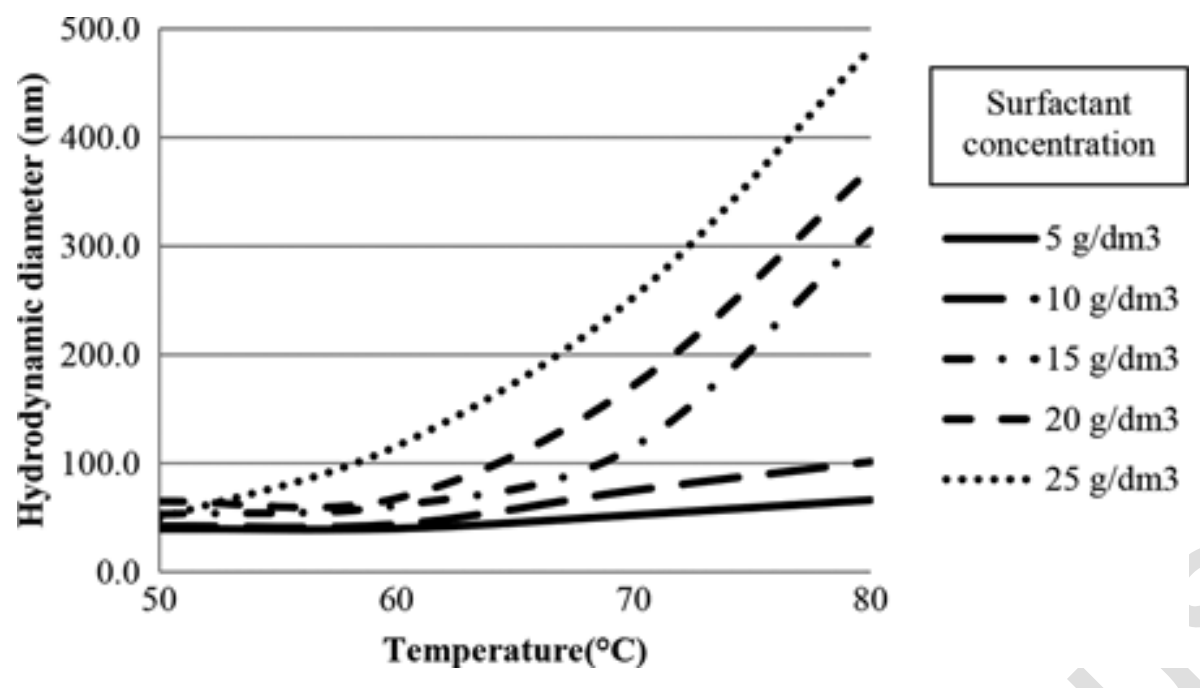


Figure 2. The distribution of the average molecular weights of the polymer, surfactants and the polymer-surfactant mixture at $25^{\circ} \mathrm{C}$.

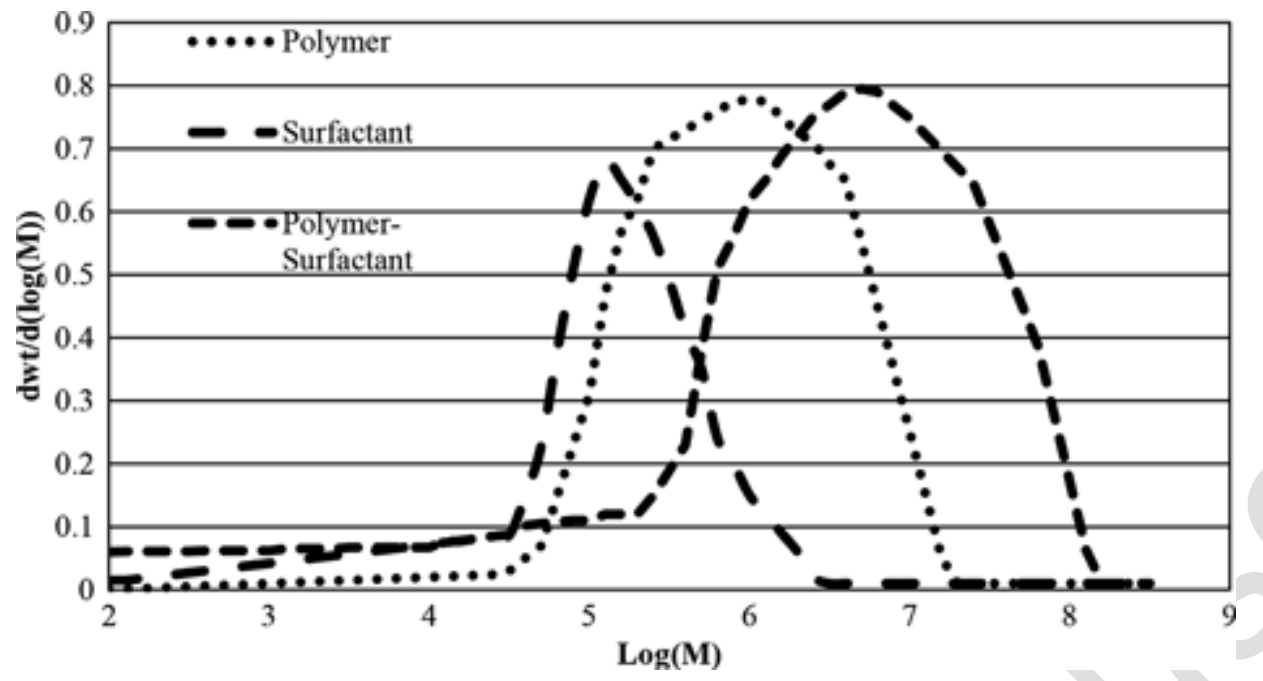


Figure 3. The distribution of the average molecular weights of the polymer-surfactant solution at different temperatures.

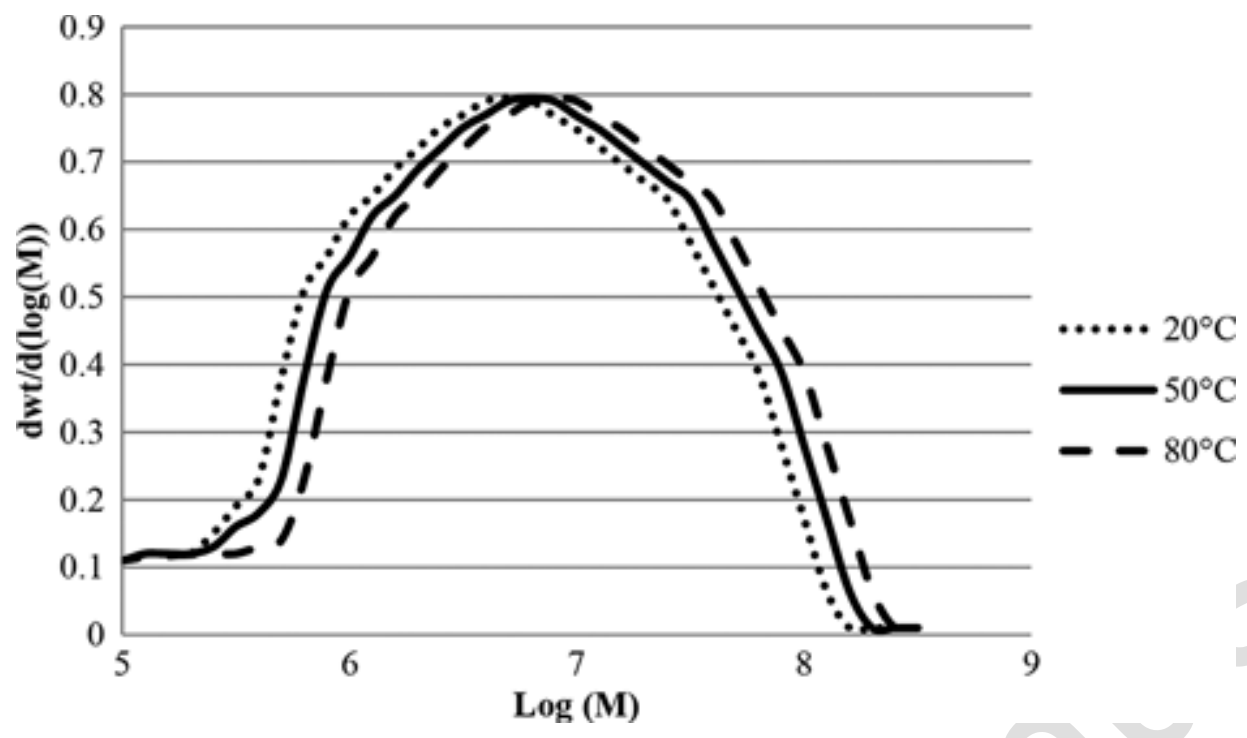

